\title{
Developmentally-programmed division of labour in the clonal invader Carpobrotus edulis
}

\author{
Sergio R. Roiloa $\cdot$ Susana Rodríguez-Echeverría $\cdot$ \\ Helena Freitas $\cdot$ Rubén Retuerto
}

Received: 16 March 2012 / Accepted: 3 January 2013 / Published online: 9 January 2013

(C) Springer Science+Business Media Dordrecht 2013

\begin{abstract}
Invasive species are one of the main causes for the loss of global biodiversity. However, the mechanisms that explain the success of invasive species remain unsolved. Clonal growth has been pointed out as an attribute that could contribute to the invasiveness of plants, however little research has been conducted to determine the importance of clonal traits in successful invaders. One of the most interesting attributes related to clonal growth is the capacity for division of labour. In this experiment we investigated the capacity for division of labour in the aggressive invader Carpobrotus edulis, and how clonal integration can contribute to the expansion of this species. Division of labour was determined by studying the degree of morphological and physiological specialization of individual ramets to a specific activity: acquisition of soil or aboveground resources and aboveground expansion. Our results showed that there is division of labour in the clonal fragments, with older ramets increasing the biomass allocated to roots (specialization in the uptake of belowground resources) and younger ramets increasing the
\end{abstract}

S. R. Roiloa $(\bowtie) \cdot$ S. Rodríguez-Echeverría $\cdot$ H. Freitas Centre for Functional Ecology, Department of Life Sciences, University of Coimbra, 3001-455 Coimbra, Portugal e-mail: sergio.roiloa@uc.pt

R. Retuerto

Unit of Ecology, University of Santiago de Compostela, 15782 Santiago de Compostela, Spain chlorophyll content and aboveground biomass (specialization in the uptake of aboveground resources). Physiological integration allows division of labour, and as consequence the overall performance of the clonal fragment was enhanced, with connected clonal fragments showing a higher total biomass than severed clonal fragments. Division of labour increased the aboveground growth of apical ramets of $C$. edulis, and therefore could contribute to an effective colonization of the surrounding area by this aggressive invader. Our study is the first exploring the role of division of labour in the expansion of an invader, and supports the idea that clonal traits could increase the invasiveness of plant species.

Keywords Biological invasions - Biomass allocation · Chlorophyll fluorescence · Clonal growth . Physiological integration $\cdot$ Spectral reflectance

\section{Introduction}

The study of biological invasions is a rapidly developing field in ecology. Nowadays, biological invasions represent one of the most serious environmental risks worldwide because alien invasive species can modify the stability and functioning of local communities, and displace native plants with the consequent loss of biodiversity (Vitousek et al. 1996; Mack et al. 2000). However, the mechanisms that explain the success of invasive species remain unsolved 
(Rejmánek and Richardson 1996; Alpert et al. 2000; Levine et al. 2003, Blackburn et al. 2011). Some plant characteristics, such as clonal growth, could explain the success of invasive species (Pyšek 1997; Liu et al. 2006; Wang et al. 2008; Roiloa et al. 2010). In fact, clonal plants are usually dominant species in terrestrial ecosystems, and play an important role in the dynamics of many plant communities and ecosystem functioning (Schmid 1990; Oborny and Bartha 1995; Kliměs et al. 1997). Key attributes related to clonal growth-such as physiological integration, habitat selection and division of labour-allow clonal plants to compete successfully in a wide range of habitats (Hartnett and Bazzaz 1983; Alpert and Stuefer 1997; Saitoh et al. 2002; Roiloa and Retuerto 2006; Roiloa et al. 2007). Despite that many of the most aggressive invasive plant species show clonal growth, little research has been conducted to determine the role of clonal traits in successful invaders (Pyšek 1997; Amsberry et al. 2000; Peltzer 2002; Liu et al. 2006, 2008; Otfinowski and Kenkel 2008; Wang et al. 2008; Roiloa et al. 2010).

Clonal growth is characterised by the asexual production of offspring (ramets) that can remain attached to the parent for a variable period of time (Pitelka and Ashmun 1985; Price and Marshall 1999). Connection allows the transport of resources between ramets. This phenomenon has been called physiological integration, which allows the clonal system to compensate heterogeneous distribution of essential resources that occurs in natural habitats. This is, to say physiological integration allows clones to act as cooperative systems, which can buffer differences in resources availability due to environmental heterogeneity (Hartnett and Bazzaz 1983; Slade and Hutchings 1987; Klimes et al. 1997; Alpert 1999). One of the most interesting attributes related to clonal growth is the capacity for division of labour under certain conditions. Division of labour in plants seems to be exclusive for clonal species and it has been traditionally defined as the capacity of specialization to acquire locally abundant resources to increase the overall performance of the clone (Alpert and Stuefer 1997; Hutchings and Wijesinghe 1997; Stuefer 1998). When the availabilities of two resources are negatively correlated, connected ramets may specialize to acquire the resource that is more abundant for each ramet. The subsequent reciprocal resource sharing between the connected ramets will increase their overall performance (Friedman and Alpert 1991; Birch and Hutchings 1994; Stuefer et al. 1996; Alpert and Stuefer 1997). In spite of the benefits of division of labour of clonal plants, no previous research has been conducted to determine the importance of ramets specialization for the invasiveness of clonal species.

In this experiment we investigated the capacity for division of labour in the aggressive invader Carpobrotus edulis, and how division of labour and physiological integration can contribute to the invasiveness of this species. We hypothesized that clonal fragments of $C$. edulis work as a cooperative system allowing its expansion into new habitats. To test this hypothesis we determined the capacity for division of labour in connected clonal fragments, and we compared performance between connected and severed clonal fragments. Division of labour was determined by estimating the degree of morphological and physiological specialization of individual ramets to a particular activity: acquisition of soil or aboveground resources, and aboveground growth. The capacity of division of labour has been studied both at morphological (Alpert and Stuefer 1997; Hutchings and Wijesinghe 1997; Stuefer et al. 1996; Stuefer 1998) and physiological level (de Kroon et al. 1996; Roiloa et al. 2007; Wang et al. 2011). This research contributes to determine role of clonality in plant invasions, which has been scarcely explored before (Pyšek 1997; Peltzer 2002; Otfinowski and Kenkel 2008; Roiloa et al. 2010). In addition, as far as we know, this is the first research pointing out division of labour as a potential trait favoring the expansion of clonal invaders.

Our specific hypotheses were: (1) Connection allows division of labour between ramets of the clonal fragment. Considering that in clonal plants acropetal transport of soil-based resources (i.e. from the older to the younger ramet) generally exceeds basipetal transport (i.e. from the younger to the older ramet) (Alpert and Mooney 1986; Price and Hutchings 1992; Alpert 1996), we predict a greater biomass allocation to roots (as an indicator of the energy allocated to harvest below-ground resources) in older compared to younger ramets of the connected clonal fragments. Also, we expect higher chlorophyll content (as an indicator of the energy allocated to harvest above-ground resources) in younger than in older ramets of the connected clonal fragments. (2) Physiological integration induces division of labour and increases the 
overall performance of the clonal fragment. We expect higher photochemical efficiency and biomass production in connected than in severed clonal fragments. As a result, connected clonal fragments will have a higher growth capacity than severed clonal fragments. Because an increase in growth rates can be associate with a higher expansion capacity in clonal invaders (Wang et al. 2008; Roiloa et al. 2010), we expect that physiological integration, and more specifically capacity for division of labour, will increase the invasive capacity of $C$. edulis.

\section{Materials and methods}

\section{Study species}

Carpobrotus edulis (L.) N.E. Br. is a mat-forming succulent plant with perennial finger-shaped leaves, with showy flowers and succulent fruits. The plant grows clonally by stolons that spread along the soil surface, producing a new ramet at every other node (Wisura and Glen 1993). New ramets can take root after direct contact with soil and can survive if disconnected with the mother ramet. Clonal propagation allows $C$. edulis effectively colonize the surrounding area. $C$. edulis is native to the Cape Region (South Africa) and is an aggressive invader in many coastal habitats around the world, having a negative effect on diversity of the native flora (D'Antonio and Mahall 1991; D’Antonio 1993; Traveset et al. 2008; Vilà et al. 2008).

\section{Experimental material}

Similarly-sized four-ramet clonal fragments of $C$. edulis were used in the experimental treatments. The clonal fragments were obtained by excising connected groups of unrooted ramets from clumps of $C$. edulis invading a sand dune system at the Mata Nacional das Dunas Quiaios (Portugal) $\left(40^{\circ} 13^{\prime} \mathrm{N}, 8^{\circ} 53^{\prime} \mathrm{W}\right.$ ) (see Costa et al. 2000 for a detailed description of the vegetation at the collection site). Eight clumps of similar size were selected for the fragments collection. At the edge of each clump two clonal fragments were collected. All the clonal fragments contained the first, second, third and fourth ramets from the apices, and therefore we ensured that fragments in all the treatments had ramets of the same age, size and developmental stage. Initial size of clonal fragments was determined using length $(21.90 \pm 0.70 \mathrm{~cm}$, mean $\pm \mathrm{SE}, \quad n=16)$ and fresh mass (60.22 \pm $3.82 \mathrm{~g}$, mean $\pm \mathrm{SE}, n=16$ ). Preliminary analysis showed no differences in initial sizes between the clonal fragments assigned to the different treatments (ANOVA for initial length of clonal fragments $F_{1}$, ${ }_{14}=0.017, P=0.899$; ANOVA for initial fresh mass of clonal fragments $F_{1,14}=0.291, P=0.598$ ). To avoid potential confounding effect of orientation in the field, all the clonal fragments were collected in the east-west direction. At the start of the experiment, each of the unrooted clonal fragments was placed in individual expanded polystyrene containers $(50 \mathrm{~cm}$ long $\times 30 \mathrm{~cm}$ width $\times 10 \mathrm{~cm}$ depth) filled with sand from a coastal dune system where $C$. edulis inhabits. C. edulis is a plant with succulent leaves and thick stolons that can act as a reservoir of resources. Unrooted ramets of $C$. edulis can survive healthy for several weeks before taking roots (personal observation). The size of the containers used in the experiment was enough to avoid confinement of the roots and to allow aboveground expansion.

\section{Experimental design}

The experiment includes "ramet age" (four levels) and "connection" (connected, severed) as main factors. The "ramet age" factor comprises four stages: ramet 1 , ramet 2 , ramet 3 and ramet 4 , corresponding with the fourth, third, second and first ramets from the apice, respectively. Therefore, ramet 1 is the oldest and ramet 4 is the youngest ramet of the fragment (see Fig. 1). In the "connection" treatment, ramets within each clonal fragment were either left connected (division of labour is allowed) or disconnected from each other (division of labour is prevented) (see Fig. 1). Immediately after the transplantation we cut the stolon halfway between every two adjacent ramets. This realistically reflects the fact that natural and human disturbance frequently break clonal fragments into smaller groups (Stuefer and Huber 1999; Latzel and Klimešová 2009). We did not observe any immediate negative effect of cutting the stolon (as sudden death or diseases). Therefore, we discarded any interference in our results derived from an initial trauma of cutting the stolon in the severed treatment. New ramets produced during the experiment were not allowed to root. Each treatment was replicated eight 


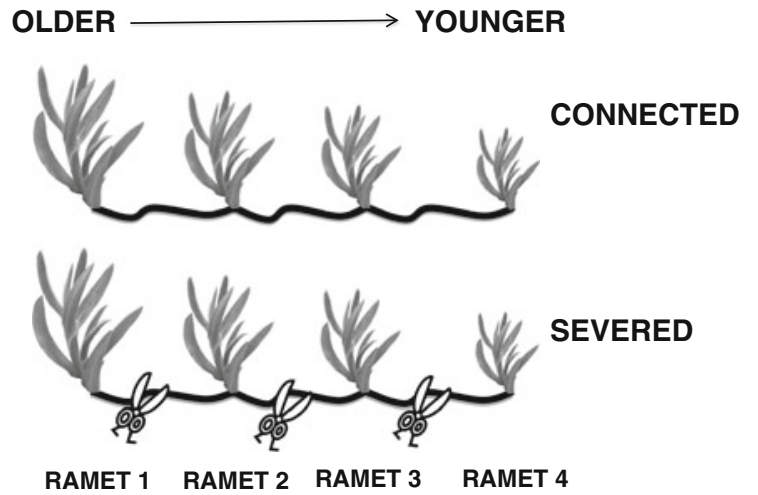

Fig. 1 Diagram of the experimental design showing the factor "connection" with two states (connected or severed) and the factor "ramet age" with four states (ramet 1, ramet 2, ramet 3 or ramet 4 ). The age (older to younger) of the ramets within the clonal fragment is shown. See text for details

times $(n=8)$. C. edulis fragments from each original clump were represented equally in each treatment.

The experiment was carried out in an open-end greenhouse at the University of Santiago de Compostela (Spain) under a natural day/night light cycle. Plants were watered regularly to prevent water stress. The experiment began on 29 April 2011 and continued for 90 days.

\section{Measurements}

\section{Leaf spectral reflectance}

We determined spectral reflectance parameters using a portable spectrometer (UniSpec Spectral Analysis System, PP Systems, Haverhill, MA). Measurements were done on a new fully formed and healthy leaf that had developed during the experiment for each individual ramet of all the clonal fragments. Reflectance spectra were calculated as the spectral radiance of the leaf divided by the radiance of a reflective white standard (Spectralon Reflectance Standard, Labsphere, North Sutton, NH). The wavelength range employed was $300-1,100 \mathrm{~nm}$. Spectral reflectance parameters were determined throughout the experiment at 30,60 and 90 days from the start of the experiment. Repeated measurements allow us to integrate the effect of time into our treatments. The spectral reflectance indices determined were: (1) PRI, the photochemical reflectance index. PRI was calculated as $\left(\mathrm{R}_{531}-\mathrm{R}_{570}\right)$ / $\left(R_{531}+R_{570}\right)$, where $R$ refers to reflectance and the subscripts to a specific spectral wavelength, in nanometers. Changes in xanthophyll cycle epoxidation state are reflected at 531 wavelength, and 570 is a reference wavelength unaffected by xanthophyll activity (Guo and Trotter 2004). PRI is significantly correlated with both net $\mathrm{CO}_{2}$ uptake and the photosynthetic radiationuse-efficiency (mol CO $\mathrm{mol}^{-1}$ photons) (Peñuelas et al. 1995; Gamon et al. 1997). PRI has also been correlated to the levels of de-epoxidised (photoprotective) xanthophyll cycle pigments (Sims and Gamon 2002; Stylinski et al. 2002). (2) CHL, chlorophyll content index, was determined as $R_{750} / R_{700}$, and is correlated to the chlorophyll content of leaves (Wood et al. 1993; Lichtenthaler et al. 1996).

\section{Chlorophyll fluorescence}

At the same dates and on the same leaves where the spectral reflectance parameters were recorded, we determined chlorophyll fluorescence parameters by the saturation pulse method (Schreiber et al. 1998), using a portable fluorometer (MINI-PAM photosynthesis yield analyzer; Walz GmbH, Effeltrich, Germany). Measuring light and saturating light pulses $(>4,000 \mu \mathrm{mol}$ photons $\mathrm{m}^{-2} \mathrm{~s}^{-1}, 0.8 \mathrm{~s}$ pulse length, actinic white light) were applied through a fiberoptic at a $60^{\circ}$ angle relative to the sample and at $12 \mathrm{~mm}$ distance from the sample. We recorded the following chlorophyll fluorescence parameters: (1) Fv/Fm, the maximum quantum yield of photosystem II (PSII), was determined as $\left(\mathrm{Fm}-\mathrm{F}_{0}\right) /$ Fm (Bolhàr-Nordenkampf et al. 1989), where $F_{0}$ and Fm are, respectively, the minimal and maximal fluorescence yield of a dark-adapted sample, with all PSII reaction centres fully open (i.e. all primary acceptors oxidized). This parameter was measured after a 30-min period of dark adaptation, which is considered to be enough for opening all PSII reaction centers (Roiloa and Retuerto 2005). Fv/Fm estimates the efficiency of excitation energy capture by open PSII reaction centres (Butler and Kitajima 1975). (2) ФPSII, the effective quantum yield of PSII, was calculated as $\left(\mathrm{F}_{\mathrm{m}}^{\prime}-\mathrm{F}_{\mathrm{t}}\right) / \mathrm{F}_{\mathrm{m}}^{\prime}$ (Genty et al. 1989), where $F_{m}^{\prime}$ is the maximal fluorescence yield reached in a pulse of saturating light with an illuminated sample (i.e. fluorescence reached when the pool of the primary quinone electron acceptor, $\mathrm{Q}_{\mathrm{A}}$, of the PSII reaction centers is fully reduced and hence photochemistry impeded), and $F_{t}$ is the measured steady-state fluorescence under a given photosynthetic photon flux density (PPFD). This parameter was measured under 
the prevailing ambient light $(172.04 \pm 11.54 \mu \mathrm{mol}$ $\mathrm{m}^{-2} \mathrm{~s}^{-1}$; mean $\left.\pm \mathrm{SE}, \mathrm{n}=192\right)$. ФPSII measures the fraction of the light absorbed by chlorophyll that is photochemically converted in PSII (Maxwell and Johnson 2000).

\section{Growth and biomass allocation}

The four individual ramets on each of the clonal fragments were numbered consecutively, from the oldest (1) to the youngest (4). At the end of the experiment, each of these individual ramets was harvested separately. Each of the individual ramets was divided into aboveground mass (leaves, the stolon internode connecting it to the next youngest ramet in the clonal fragment, and new ramet produced) and roots. Each of these fractions was dried to constant mass at $60{ }^{\circ} \mathrm{C}$ and weighed. Total mass (aboveground mass + root mass) was calculated for individual ramets. Proportional allocation of biomass to roots, determined as the root mass ratio (RMR = root mass/ total mass), was calculated for individual ramets. Aboveground mass and root mass were determined for each clonal fragment by adding up the data of the four individual ramets. Total mass and the RMR were also calculated for each clonal fragment.

Statistical analysis

Prior to analyses, as a requirement for the parametric tests, normality and homoscedasticity of the data were checked using Kolmogorov-Smirnov and Levene tests, respectively. Neither root mass nor RMR of individual ramets, or their transformations, met the requirements of parametric tests. Differences between treatments in aboveground mass and total mass of individual ramets were analysed using two-way analysis of variance (ANOVA) with "ramet age" and "connection" as main factors. We used the Scheirer-Ray-Hare test (Dyham 1999) (the non-parametric equivalent of two-way ANOVA) to examine differences in root mass and RMR of the individual ramets, with "ramet age" and "connection" as main factors. Differences in chlorophyll fluorescence (Fv/Fm and ФPSII) and spectral reflectance (PRI and CHL) parameters for individual ramets were analyzed by two way analysis of variance with repeated measures (ANOVAR), with "ramet age" and "connection" as between-subject effects, and "time" as the within-subject effect.
Differences in aboveground mass, root mass, total mass and RMR for clonal fragments were tested by two-way ANOVAs, with "ramet age" and "connection" as main factor.

Significance level was set at $P<0.05$. Statistical test were performed with IBM SPSS Statistics 19.0 (IBM Corporation, Armonk, NY, USA).

\section{Results}

Individual ramets

\section{Leaf spectral reflectance and chlorophyll fluorescence}

The chlorophyll content index (CHL) was significantly affected by "ramet age". CHL was higher in younger ramets than in older ramets (Table 1; Fig. 2a). The interaction "ramet age" $\times$ "connection" for CHL was not significant. However, additionally, we examined the effect of "ramet age" on CHL separately for the connected and severed treatment by one-way ANOVAs, with "ramet age" as main factor. These separate ANOVAs confirmed different responses of the connected and severed treatment. While CHL values were significantly higher in younger ramets of the connected treatment (ANOVA $F_{3,92}=6.114, P=0.001$ ), there were no significant differences in the severed treatment (ANOVA $F_{3,92}=1.436, P=0.237$ ).

The remaining physiological parameters measured, photochemical reflectance index (PRI) and effective (ФPSII) and maximum (Fv/Fm) quantum yield of PSII were significantly affected by "connection". Connected ramets showed a higher PRI, ФPSII and Fv/Fm than severed ramets (Table 1; Figs. 2b-d, 3b-d).

"Time" had a significant effect on CHL, PRI and ФPSII (Table 1; Fig. 3). There was a significant effect of the interaction between "connection" and "time" on maximum quantum yield of PSII (Fv/Fm), with an increase of $\mathrm{Fv} / \mathrm{Fm}$ in connected ramets and a decrease in severed ramets (Table 1; Fig. 3d).

\section{Growth and biomass allocation}

Aboveground and total mass increased significantly with "ramet age" (Table 2; Fig. 4). Aboveground and total mass was significantly higher in connected than in severed ramets (Table 2; Fig. 4). For root mass and RMR, the oldest ramets showed significantly higher 
Table 1 Results of the repeated-measure ANOVA for chlorophyll content index (CHL), photochemical reflectance index (PRI), effective (ФPSII) and maximum (Fv/Fm) quantum yield of photosystem II of individual ramets

\begin{tabular}{|c|c|c|c|c|c|c|c|c|c|c|c|c|}
\hline & \multicolumn{3}{|c|}{ CHL } & \multicolumn{3}{|l|}{ PRI } & \multicolumn{3}{|c|}{ ФPSII } & \multicolumn{3}{|c|}{$\mathrm{Fv} / \mathrm{Fm}$} \\
\hline & $d f$ & $F$ & $P$ & $d f$ & $F$ & $P$ & $d f$ & $F$ & $P$ & $d f$ & $F$ & $P$ \\
\hline \multicolumn{13}{|l|}{ Between-subject effect } \\
\hline Ramet age & 3 & 4.607 & 0.006 & 3 & 0.151 & 0.929 & 3 & 0.776 & 0.512 & 3 & 0.369 & 0.776 \\
\hline Connection & 1 & 0.676 & 0.415 & 1 & 14.199 & $<0.001$ & 1 & 8.075 & 0.006 & 1 & 6.196 & 0.016 \\
\hline Ramet age $\mathrm{x}$ connection & 3 & 0.337 & 0.798 & 3 & 0.273 & 0.844 & 3 & 0.109 & 0.955 & 3 & 0.714 & 0.548 \\
\hline Error & 56 & & & 56 & & & 56 & & & 56 & & \\
\hline \multicolumn{13}{|l|}{ Within-subject effect } \\
\hline Time & 2 & 3.144 & 0.047 & 2 & 40.234 & $<0.001$ & 2 & 80.601 & $<0.001$ & 2 & 0.267 & 0.776 \\
\hline Ramet age $\times$ time & 6 & 1.587 & 0.157 & 6 & 1.316 & 0.256 & 6 & 0.065 & 0.999 & 6 & 1.080 & 0.379 \\
\hline Connection $\times$ time & 2 & 0.183 & 0.833 & 2 & 0.325 & 0.723 & 2 & 0.289 & 0.750 & 2 & 3.674 & 0.028 \\
\hline Ramet age $\times$ connection $\times$ time & 6 & 0.724 & 0.631 & 6 & 0.736 & 0.621 & 6 & 0.104 & 0.996 & 6 & 0.693 & 0.656 \\
\hline Error & 112 & & & 112 & & & 112 & & & 112 & & \\
\hline
\end{tabular}

$P<0.05$ are in bold. See Figs. 2, 3 for data
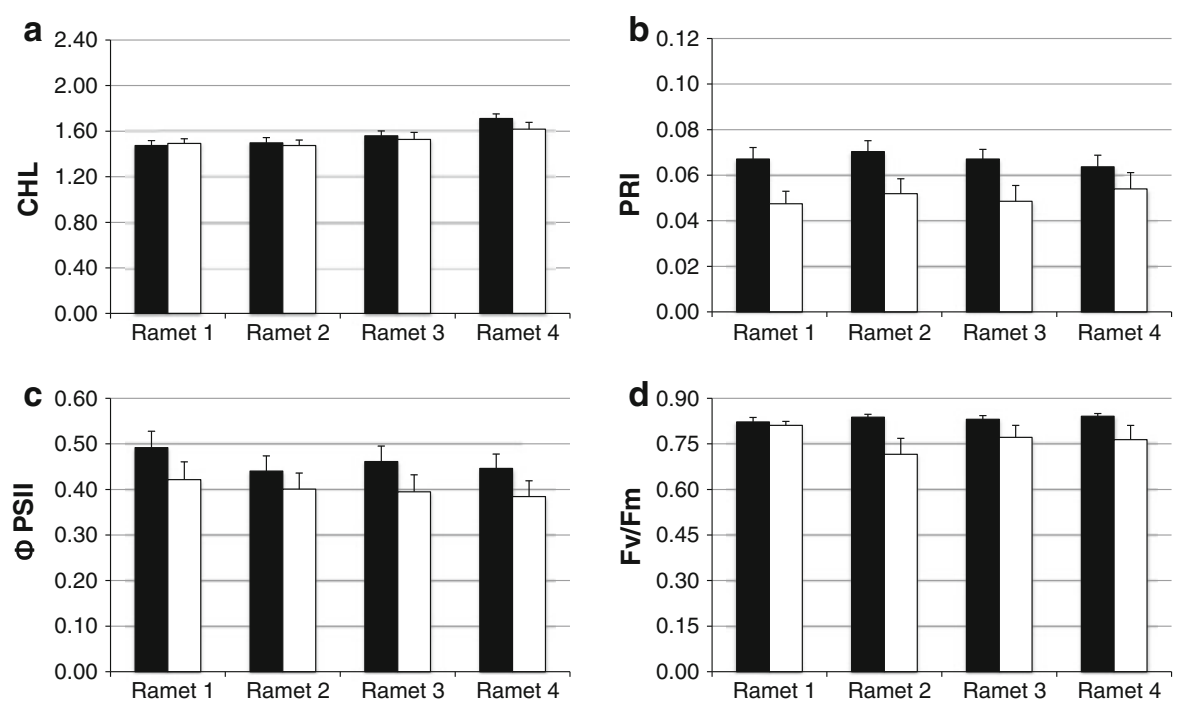

Fig. 2 Spectral reflectance (CHL and PRI, top panels $\mathbf{a}, \mathbf{b})$ and chlorophyll fluorescence (ФPSII and Fv/Fm, bottom panels c, d) parameters for connected (filled bars) and severed (empty bars)

individual ramets (mean $\pm \mathrm{SE}$ ). Average values of the three dates of measurements (30, 60, 90 days) are represented. See Table 1 for ANOVA results

values than younger ramets only in the connected treatment (Table 2; Fig. 4).

\section{Clonal fragments}

significantly higher for connected clones than for severed clones (Fig. 5a-c). However, no differences between connected and severed clones were found for the $\operatorname{RMR}\left(F_{1,14}=3.841, P=0.070\right.$; Fig. $\left.5 \mathrm{~d}\right)$.

\section{Growth and biomass allocation}

At clonal fragment level, aboveground mass $\left(F_{1,14}=\right.$ 4.618, $P=0.050)$, root mass $\left(F_{1}, 14=6.296, P=\right.$ $0.025)$ and total mass $\left(F_{1,14}=5.149, P=0.040\right)$ were

\section{Discussion}

We found specialization of older ramets in root production and younger ramets in chlorophyll content. 

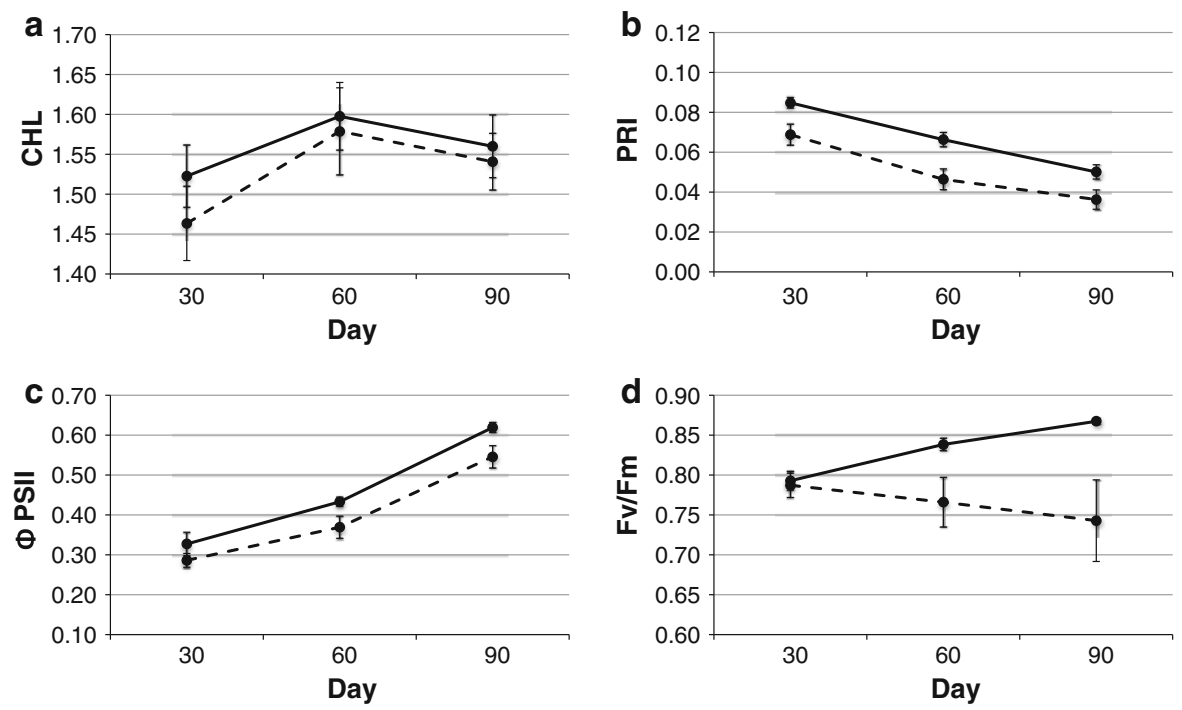

Fig. 3 Time course of mean values $( \pm \mathrm{SE})$ of spectral reflectance (CHL and PRI, top panels a, b) and chlorophyll fluorescence (ФPSII and Fv/Fm, bottom panels $\mathbf{c}, \mathbf{d}$ ) parameters

for connected (solid lines) and severed (dashed lines) treatments. Average values of the four ramets within each clonal fragment are represented. See Table 1 for ANOVA results

Table 2 Results of the two-way ANOVA and Scheirer-Ray-Hare test to check for the effect of ramet age and connection on aboveground mass and total mass (ANOVA), and root mass and root mass ratio (SRH test) of individual ramets

\begin{tabular}{|c|c|c|c|c|c|c|c|c|c|c|c|c|}
\hline & \multicolumn{3}{|c|}{ Above-ground mass } & \multicolumn{3}{|c|}{ Total mass } & \multicolumn{3}{|c|}{ Root mass } & \multicolumn{3}{|c|}{ Root mass ratio } \\
\hline & $d f$ & $F$ & $P$ & $d f$ & $F$ & $P$ & $d f$ & $S S / M S_{\text {total }}$ & $P$ & $d f$ & $S S / M S_{\text {total }}$ & $P$ \\
\hline Ramet age & 3 & 12.561 & $<0.001$ & 3 & 17.681 & $<0.001$ & 3 & 20.207 & $<0.001$ & 3 & 10.964 & 0.012 \\
\hline Connection & 1 & 8.828 & 0.004 & 1 & 9.985 & 0.003 & 1 & 1.347 & 0.246 & 1 & 2.214 & 0.137 \\
\hline Ramet age $\times$ connection & 3 & 0.141 & 0.935 & 3 & 1.497 & 0.225 & 3 & 17.180 & 0.001 & 3 & 20.127 & $<0.001$ \\
\hline Error & 56 & & & & & & & & & & & \\
\hline
\end{tabular}

$P<0.05$ are in bold. See Fig. 4 for data

This supports our first hypothesis that connection allowed division of labour between ramets of the clonal fragment. As predicted, older ramets allocated more biomass to roots than younger ramets, and the chlorophyll content was greater in the younger than in the older ramet. These differences in RMR and chlorophyll content between ramets within the clone were detected mainly in the connected treatment: connection allows ramets to undertake different tasks within the clonal fragment. While older ramets specialize in acquisition of soil-based resources (determined by the increase in RMR), younger ramets specialize in aboveground expansion (determined by the reduction in RMR) and in harvesting aboveground resources (determined by a higher chlorophyll content). We detected a greater investment in aboveground structures by connected younger ramets, and a high proportion of aboveground mass in $C$. edulis is invested in stolon growth. Therefore, the transfer of a greater proportion of mass to aboveground parts would be expected to lead to greater lateral expansion of stolons. In a recent experiment with $C$. edulis Roiloa et al. (2010) have found an association between the increase in total biomass and the production of new ramets, supporting the idea that an increase of the biomass allocated to above-ground structures is directly associated with the production of new ramets and, as consequence, with lateral expansion. Similarly, in an experiment with the stoloniferous Glechoma hederacea, Roiloa and Hutchings (2012) have proposed that clonal fragments could develop a form of division of labour in which ramets 


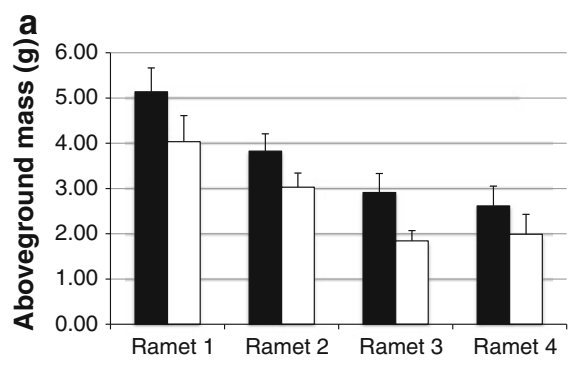

b

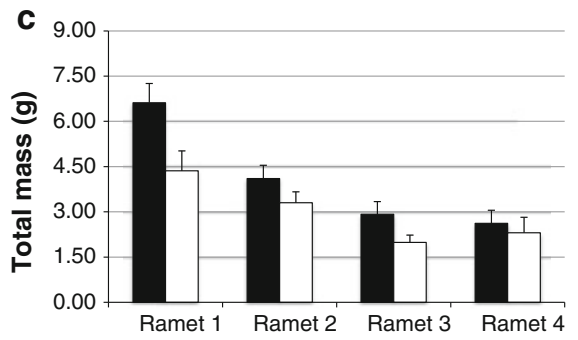

Fig. 4 Aboveground mass (a) root mass (b), total mass (c) and the proportional biomass allocated to roots estimated as the root mass ratio (d) of connected (filled bars) and severed (empty

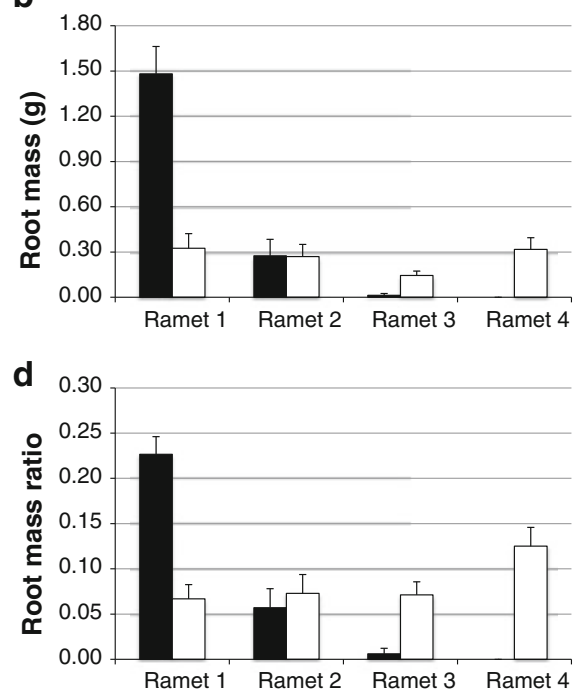

bars) individual ramets (mean $\pm \mathrm{SE}$ ). See Table 2 for ANOVA and Scheirer-Ray-Hare test results

Fig. 5 Aboveground mass (a) root mass (b), total mass (c) and the proportional biomass allocated to roots estimated as the root mass ratio (d) of clonal fragments (mean $\pm \mathrm{SE})$. Connected treatment (filled bars) and severed treatment (empty bars) are shown. See text for ANOVA results

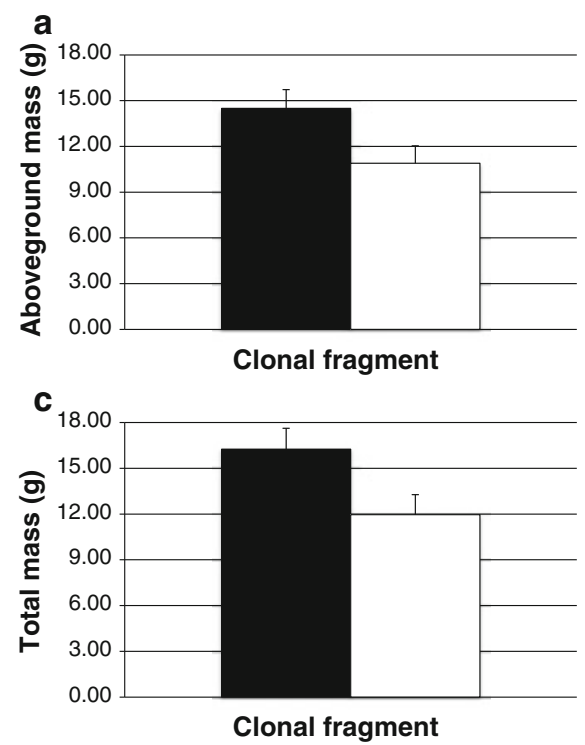

b

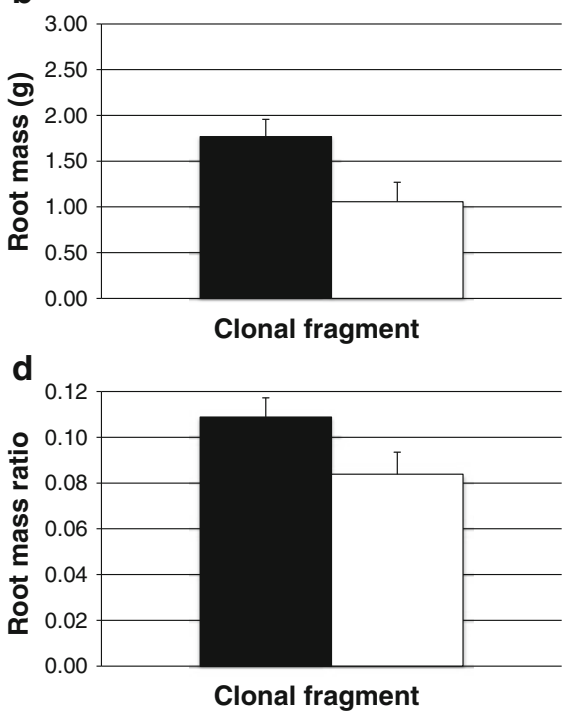

that were not allowed to take root specialized in lateral expansion, while ramets that were allowed to take root specialized in acquisition of soil-based resources. In our experiment, the increase in chlorophyll content detected in younger ramets could contribute to their aboveground growth, as the higher light energy harvest was mainly allocated to aboveground structures. Roiloa et al. (2007) also reported an increase in the chlorophyll content of younger ramets of Fragaria chiloensis as a specialization to acquire light. This physiological specialization detected in our experiment supports that division of labour can be also detected in physiological traits (de Kroon et al. 1996; Roiloa et al. 2007; Wang et al. 2011).

Division of labour has been extensively studied in clonal plants, and it has been mainly associated with a heterogeneous distribution of resources. Most of the studies have used a design with two resources 
negatively correlated in the space to induce division of labour. In this situation, ramets specialize to acquire the resource that is more abundant to them, and the subsequent reciprocal resource sharing increases the overall performance of the clone. This prediction is based on the logical fact that the acquisition of the abundant resource is likely to be more efficient than the acquisition of the scarce resource (Friedman and Alpert 1991; Birch and Hutchings 1994; Stuefer et al. 1996; Alpert and Stuefer 1997; Hutchings and Wijesinghe 1997; Stuefer 1998). Our study reports division of labour in a homogeneous environment, with all the ramets of the clone subjected to identical growing conditions and having access to identical amount of below and aboveground resources. Similarly, previous research has showed functional and structural specialization not environmentally induced in rhizomatous species (Schmid 1990; Stuefer 1998). As far as we know, we report here the first evidence that division of labour can be also developed under homogeneous conditions by a stoloniferous species. This finding is significant, because it indicates that the benefits of clonal integration are not only important under heterogeneous conditions, as it has been widely proposed (Price and Marshall 1999; Pennings and Callaway 2000; Saitoh et al. 2002; Roiloa and Retuerto 2006), but also relevant in homogeneous environments (Stuefer 1998). Ramet specialization reported in our experiment can be defined as a developmentally programmed division of labour (Stuefer 1998). This is an inherent division of labour, characterized by the presence of specialization implicit in the ontogeny of the ramets. Therefore, this type of division of labour is expressed in absence of induction due to environmental heterogeneity (Stuefer 1998).

We found an increase in photochemical efficiency and growth in connected fragments. This supports our second hypothesis that division of labour, mediated by physiological integration, increases the overall performance of the clonal fragment. As we expected, the photochemical efficiency and biomass production were higher in connected than in severed clonal fragments. The movement of resources between connected ramets of clonal plants has been widely described and generally confers net benefits to the whole clone (e.g. Hartnett and Bazzaz 1983; Alpert and Mooney 1986; Slade and Hutchings 1987; Birch and Hutchings 1994; Alpert 1999; Saitoh et al. 2002;
Roiloa and Retuerto 2006). Physiological traits can be considered as a sensible indicator of plant responses to the environment, and usually its effect on plants can be detected earlier at physiological than at morphological level. The current research contributes to prove that the benefits of clonal integration can be detected at physiological level (Hartnett and Bazzaz 1983; Roiloa and Retuerto 2006; Roiloa et al. 2007; Liu et al. 2008; Zhang et al. 2009). Roiloa and Retuerto (2006) have reported a similar benefit of integration in photochemical efficiency in a study with the clonal Fragaria vesca. In our study, the benefits of connection showed by clonal fragments in terms of photochemical efficiency were transferred into benefits in biomass production. As a result of these benefits at physiological and morphological level connected clonal fragments could have a higher growth rate, and therefore colonization capacity, than severed clonal fragments.

In short, connected clonal fragments of $C$. edulis showed developmentally programmed division of labour, and their photochemical efficiency and growth was enhanced by integration. This benefit of division of labour could be closely associated with the invasive expansion of $C$. edulis. The importance of clonal integration in plant invaders has been scarcely explored before (Amsberry et al. 2000; Peltzer 2002; Otfinowski and Kenkel 2008; Wang et al. 2008; Aguilera et al. 2010; Roiloa et al. 2010), and our study is the first exploring the idea that division of labour could contributes to the expansion of an invader, and therefore that clonal traits could increase the invasiveness of plant species (Pyšek 1997; Liu et al. 2006).

Acknowledgments S. R. R. was financed by a grant of the Portuguese Foundation for Science and Technology (FCT) (Reference: SFRH/BPD/79599/2011) co-funded by the European Social Fund of the European Union. We are grateful to three anonymous referees for their valuable comments on a previous version of this paper.

\section{References}

Aguilera AG, Alpert P, Dukes JS, Harrington R (2010) Impacts of the invasive plant Fallopia japonica (Houtt.) on plant communities and ecosystem processes. Biol Invasions 12:1243-1252

Alpert P (1996) Nutrient sharing among ramets increases clonal growth in Fragaria chiloensis. J Ecol 84:395-406

Alpert P (1999) Clonal integration in Fragaria chiloensis differs between populations: ramets from grassland are selfish. Oecologia 120:69-76 
Alpert P, Mooney HA (1986) Resource sharing among ramets in the clonal herb, Fragaria chiloensis. Oecologia 70:227233

Alpert P, Stuefer JF (1997) Division of labour in clonal plants. In: de Kroon H, van Groenendael J (eds) The ecology and evolution of clonal plants. Backhuys Publishers, Leiden, pp 137-154

Alpert P, Bone E, Holzapfel C (2000) Invasiveness, invasibility, and the role of environmental stress in preventing the spread of non-native plants. Perspect Plant Ecol Evol Syst 3:52-66

Amsberry L, Baker MA, Ewanchuk PJ, Bertness MD (2000) Clonal integration and the expansion of Phragmites australis. Ecol Appl 10:1110-1118

Birch CPD, Hutchings MJ (1994) Exploitation of patchily distributed soil resources by the clonal herb Glechoma hederacea. J Ecol 82:653-664

Blackburn TM, Pyšek P, Bacher S, Carlton JT, Duncan RP, Jaroší V, Wilson JRU, Richardson DM (2011) A proposed unified framework for biological invasions. Trends Ecol Evol 26:333-339

Bolhàr-Nordenkampf HR, Long SP, Baker NR, Öquist G, Scheiber U, Lechner EG (1989) Chlorophyll fluorescence as a probe of the photosynthetic competence of leaves in the field: a review of current instrumentation. Funct Ecol 3:497-514

Butler W, Kitajima M (1975) Fluorescence quenching in photosystem II of chloroplasts. Biochim Biophys Acta 376:116-125

Costa JC, Lousã M, Capelo J, Espírito Santo MD, Izco Sevillano J, Arsénio P (2000) The coastal vegetation of the Portuguese divisory sector: dunes cliffs and low-scrub communities. Finisterra XXXV 69:69-93

D'Antonio CM (1993) Mechanisms controlling invasion of coastal plant communities by the alien succulent Carpobrotus edulis. Ecology 74:83-95

D'Antonio CM, Mahall BE (1991) Root profiles and competition between the invasive, exotic perennial, Carpobrotus edulis, and two native shrub species in California coastal scrub. Am J Bot 78:885-894

de Kroon H, Fransen B, van Rheenen JWA, van Dijk A, Kreulen R (1996) High levels of inter-ramet water translocation in two rhizomatous Carex species, as quantified by deuterium labelling. Oecologia 106:73-84

Dyham C (1999) Choosing and using statistics: A biologist's guide. Blackwell Science, London, pp 131-136

Friedman D, Alpert P (1991) Reciprocal transport between ramets increases growth of Fragaria chiloensis when light and nitrogen occur in separate patches but only if patches are rich. Oecologia 86:76-80

Gamon JA, Serrano I, Surfus JS (1997) The photochemical reflectance index: an optical indicator of photosynthetic radiation use efficiency across species, functional types, and nutrient levels. Oecologia 112:492-501

Genty BE, Briantais JM, Baker NR (1989) The relationship between the quantum yield of photosynthetic electron transport and quenching of chlorophyll fluorescence. Biochim Biophys Acta 990:87-92

Guo J, Trotter CM (2004) Estimating photosynthetic light-use efficiency using the photochemical reflectance index: variations among species. Funct Plant Biol 31:255-265
Hartnett DC, Bazzaz FA (1983) Physiological integration among intraclonal ramets in Solidago canadensis. Ecology 64:779-788

Hutchings MJ, Wijesinghe DK (1997) Patchy habitats, division of labour and growth dividends in clonal plants. Trends Ecol Evol 12:390-394

Kliměs L, Kliměsova J, Hendriks R, van Groenendael J (1997) Clonal plant architecture: a comparative analysis of form and function. In: de Kroon H, van Groenendael J (eds) The ecology and evolution of clonal plants. Backhuys Publishers, Leiden, pp 1-29

Latzel V, Klimešová J (2009) Fitness of reprouters versus seeders in relation to nutrient availability in two Plantago species. Acta Oecol 35:541-547

Levine JM, Vilà M, D’Antonio CM, Dukes JS, Grigulis K, Lavorel S (2003) Mechanisms underlying the impacts of exotic plant invasions. Proc R Soc B 270:775-781

Lichtenthaler HK, Gitelson A, Lang M (1996) Non-destructive determination of chlorophyll content of leaves of a green and an Aurea mutant of tobacco by reflectance measurements. J Plant Physiol 148:483-493

Liu J, Dong M, Miao S, Li Z, Song M, Wang R (2006) Invasive alien plants in China: role of clonality and geographical origin. Biol Invasions 8:1461-1470

Liu J, He WM, Zhang SM, Liu FH, Dong M, Wang RQ (2008) Effect of clonal integration on photosynthesis of the invasive clonal plant Alternanthera philoxeroides. Photosynthetica 46:299-302

Mack RN, Simberloff D, Lonsdale WM, Evans H, Clout M, Bazzaz FA (2000) Biotic invasions: causes, epidemiology, global consequences, and control. Ecol Appl 10:689-710

Maxwell K, Johnson GN (2000) Chlorophyll fluorescence-a practical guide. J Exp Bot 51:659-668

Oborny B, Bartha S (1995) Clonality in plant communities-an overview. Abstr Bot 19:115-127

Otfinowski R, Kenkel NC (2008) Clonal integration facilitates the proliferation of smooth brome clones invading northern fescue prairies. Plant Ecol 199:235-242

Peltzer DA (2002) Does clonal integration improve competitive ability? A test using aspen (Populus tremuloides [Salicaceae]) invasion into prairie. Am J Bot 89:494-499

Pennings SC, Callaway RM (2000) The advantages of clonal integration under different ecological conditions: a community-wide test. Ecology 81:709-716

Peñuelas J, Filella I, Gamon JA (1995) Assessment of photosynthetic radiation-use efficiency with spectral reflectance. New Phytol 131:291-296

Pitelka LF, Ashmun JW (1985) Physiology and integration of ramets in clonal plants. In: Jackson JBC, Buss LW, Cook RE (eds) Population biology and evolution of clonal organisms. Yale University Press, New Haven, pp 339_ 437

Price EAC, Hutchings MJ (1992) The causes and developmental effects of integration and independence between different parts of Glechoma hederacea clones. Oikos 63:376-386

Price EAC, Marshall C (1999) Clonal plants and environmental heterogeneity. Plant Ecol 141:3-7

Pyšek P (1997) Clonality and plant invasion: can a trait make a difference? In: de Kroon H, van Groenendal J (eds) The ecology and evolution of clonal plants. Backhuys Publishers, Leiden, pp 405-427 
Rejmánek M, Richardson DM (1996) What attributes make some plant species more invasive? Ecology 77:1655-1661

Roiloa SR, Hutchings MJ (2012) The effects of rooting frequency and position of rooted ramets on plasticity and yield in a clonal specie: an experimental study with Glechoma hederacea. Ecol Res 27:145-152

Roiloa SR, Retuerto R (2005) Presence of developing ramets of Fragaria vesca increase photochemical efficiency in parent ramets. Int J Plant Sci 166:795-803

Roiloa SR, Retuerto R (2006) Physiological integration ameliorates effects of serpentine soils in the clonal herb Fragaria vesca. Physiol Plantarum 128:662-676

Roiloa SR, Alpert P, Nishanth T, Hancock G, Bhowmik P (2007) Greater capacity for division of labour in clones of Fragaria chiloensis from patchier habitats. J Ecol 95:397-405

Roiloa SR, Rodríguez-Echeverría S, de la Peña E, Freitas H (2010) Physiological integration increases survival and growth of the clonal invader Capobrotus edulis. Biol Invasions 12:1815-1823

Saitoh T, Seiwa K, Nishiwaki A (2002) Importance of physiological integration of dwarf bamboo to persistence in forest understorey: a field experiment. J Ecol 90:78-85

Schmid B (1990) Some ecological and evolutionary consequences of modular organization and clonal growth in plants. Evol Trend Plant 4:25-34

Schreiber U, Bilger W, Hormann H, Neubauer C (1998) Chlorophyll fluorescence as a diagnostic tool: basics and some aspects of practical relevance. In: Raghavendra AS (ed) Photosynthesis. A Comprehensive Treatise. Cambridge University Press, Cambridge, pp 320-336

Sims DA, Gamon JA (2002) Relationships between leaf pigment content and spectral reflectance across a wide range of species, leaf structures and developmental stages. Remote Sens Environ 81:337-354

Slade AJ, Hutchings MJ (1987) An analysis of the costs and benefits of physiological integration between ramets in the clonal perennial herb Glechoma hederacea. Oecologia 73:425-431

Stuefer J (1998) Two types of division of labour in clonal plants: benefits, costs and constraints. Perspect Plant Ecol Evol Syst 1:47-60
Stuefer JF, Huber H (1999) The role of stolon internodes for ramet survival after clone fragmentation in Potentilla anserina. Ecol Lett 2:135-139

Stuefer JF, de Kroon H, During HJ (1996) Exploitation of environmental heterogeneity by spatial division of labour in a clonal plant. Funct Ecol 10:328-334

Stylinski CD, Gamon JA, Oechel WC (2002) Seasonal patterns of reflectance indices, carotenoid pigments and photosynthesis of evergreen chaparral species. Oecologia 131:366374

Traveset A, Moragues E, Valladares F (2008) Spreading of the invasive Carpobrotus aff. acinaciformis in Mediterranean ecosystems: the advantage of performing in different light environments. Appl Veg Sci 11:45-54

Vilà M, Siamantziouras AKD, Brundu G, Camarda I, Lambdon P, Médail F, Moragues E, Suehs CM, Traveset A, Troumbis AY, Hulme PE (2008) Widespread resistance of Mediterranean island ecosystems to the establishment of three alien species. Divers Distrib 14:839-851

Vitousek PM, D’Antonio CM, Loope LL, Westbrooks R (1996) Biological invasions as global environmental change. Am Sci 84:468-478

Wang N, Yu FH, Li PX, He WM, Liu FH, Liu JM, Dong M (2008) Clonal integration affects growth, photosynthetic efficiency and biomass allocation, but not the competitive ability, of the alien invasive Alternanthera philoxeroides under severe stress. Ann Bot 101:671-678

Wang Z, Li Y, During HJ, Li L (2011) Do clonal plants show greater division of labour morphologically and physiologically at higher patch contrasts? PLoS One 6(9):e25401. doi:101371/journal.pone.0025401

Wisura W, Glen HF (1993) The South African species of Carpobrotus (Mesembryanthema-Aizoaceae). Contrib Bolus Herb 15:76-107

Wood CW, Reeves DW, Himelrick DG (1993) Relationships between chlorophyll meter readings and leaf chlorophyll concentration, $\mathrm{N}$ status, and crop yield: a review. Proc Agron Soc N Z 23:1-9

Zhang YC, Zhang QY, Luo P, Wu N (2009) Photosynthetic response of Fragaria orientalis in different water contrast clonal integration. Ecol Res 24:617-625 